\title{
Entre a comicidade, o senso comum e a disidência. A revista Humor como espaço controversial (1978-1980).
}

\section{Between laugh, common sense and dissent. Humor magazine as a controversial space (1978-1980).}

Eduardo Raíces ${ }^{1}$

\author{
RESUMO
}

O artículo aborda a etapa inicial da revista Humor, entre 1978 y 1980, durante a última ditadura militar na Argentina (1976-1983). Neste sentido, procuramos estudar a intervenção do seu público através da seção de cartas dos leitores. Nosso objectivo foi o análise das polémicas dadas na seção; afirmamos que ela foi un espaço de restabelecimento de vínculos sociais interrumpidos pela repressão estatal. Assim mesmo, foram una instancia para que Humor pudesse evaluar os efeitos dos contéudos fornecidos ao leitor. $\mathrm{O}$ análise teve como resultado a deteção de duas polémicas sobre questões públicas na seccão. A primeira supõe a representaçao do horror desde o humor gráfico, no caso do genocidio judeu (Shoah); a segunda refere-se a cómo os quadrinhos humorísticos abordam ao outro, entendido pelas classes populares. As duas polémicas forçam a Humor a explicitar os valores do seu projeto editorial e põem em evidéncia os disensos do seu público participante como sinal da heterogeneidade de sus opinhoes. Nosso aporte busca, então, restituir complexidade a visão consolidada com respeito aos actores participantes em Humor como expressão opositora a ditadura.

Palavras-Chave: Humor. Revistas. Ditadura militar.

\section{ABSTRACT}

This paper deals on initial phase of argentine Humor magazine, between 1978 and 1980, during the military dictatorship period (1976-1983). Our text is focused on significative actores implied with the magazine. In that sense, we research the intervention of its public through reader's letters section. Our goal was to analyze controversies in that section. We assert it was a useful space in restablishing broken social links resulting from state repression. In addition to this, the reader's section was a way so Humor could evaluate the effects of contents offered to its public.The analysis let us detect two controversies developed about relevant public matters. The first one concerns horror representation, relating the jewish genocide (Shoah); the second one dealt with how comic cartoons depicts the Other in the shape of popular classes. Both controversies oblige Humor to state explicitly the values of its editorial project and also evidenced a notorious dissent between its readers. Our contribution is intended to bring complexity to an assumed vision that relates directly actors connected with Humor magazine with oposition to dictatorial government.

Keywords: Humor. Magazines. Military dictatorship

\footnotetext{
${ }^{1}$ Consejo Nacional de Investigaciones Científicas y Técnicas (CONICET)- Instituto de Desarrollo Económico y Social (IDES).
} 


\section{Introducción}

Entre los factores relevantes a la hora de contabilizar la conformación de discursos públicos de oposición y disidencia con las dictaduras militares en el Cono Sur, suele tomarse en consideración la actividad ejercida por la prensa gráfica. Dentro de este campo, se ha destacado el papel jugado por las revistas de humor y sátira política las cuales pudieron, a través de los sentidos indirectos y -más o menos- solapados del humorismo, manifestar formas de desavenencia con los dictados oficiales. En este sentido, pueden contarse los casos de revistas como $O$ Pasquim en Brasil, El Dedo en Uruguay y Humor en Argentina en un abierto a fines de la década del 60 hasta mediados de la del 80.

Esta última, dirigida por Andrés Cascioli, supo casi desde su comienzo en 1978, en plena dictadura, posicionarse como parte de las expresiones mediáticas disidentes, hasta llegar a un nivel masivo de ventas en sintonía con la crisis del régimen castrense y el avance hacía la recuperación del régimen constitucional, producido en 1983. En los años posteriores inició un lento camino descendiente, culminado con su desaparición a fines de la década del 90.

Desde entonces, las lecturas de Humor, desde los medios pero también desde la academia, tendieron a volverla un caso emblemático de la "resistencia a la dictadura", opuesto a otras franjas de la prensa juzgadas por su complicidad y oportunismo durante el septenio militar. Esta perspectiva predominante nos estimuló a indagar lo que la relectura de la revista comenzó a sugerir, de acuerdo a cierto "ruido" que había comenzado a causarnos aquella versión. Fue centrando la observación en los actores relevantes en la vida de la revista que llegamos al análisis de su staff como de la sección de correspondencia, para relevar las controversias entabladas en la revista por sus lectores.

Nuestra construcción del objeto nos llevó, en primer lugar, a establecer una periodización histórica. Así, la etapa abordada (1978-1980) contempla el desarrollo incipiente y tentativo de una revista que combinaba el humor costumbrista y la sátira política, con la prudencia que las condiciones políticas aconsejaban. A través de los límites impuestos por la censura oficial refrendados por una autocensura presente en buena parte de la prensa- (AVELLANEDA, 1986), Humor fue tanteando las posibilidades de tematizar distintos tópicos sin sufrir represalias directas por parte del estado. Un ejemplo de esta búsqueda es el tratamiento satírico de los efectos de las políticas económicas neoconservadoras oficiales, como parte de planteos críticos presentes ya en algunos diarios y publicaciones "serias" de la época. A estos contenidos, se sumaban apartados destinados a la crítica de espectáculos y entrevistas a personalidades del mismo campo, que denotaban en conjunto un intento de establecer criterios de la "verdadera cultura", frente a lo que se veía como una "mediocridad" alentada por los grandes medios, bajo la 
aquiescencia oficial. A diferencia de otras publicaciones de entretenimiento, Humor incorpora la reflexión cultural no solamente desde el lenguaje propuesto por su título, y la convierte en una de las bases desde las cuales organiza su discurso disidente.

La combinación de distintos factores contextuales y otros propios de la dinámica de la revista, produjeron un ostensible despegue de las ventas de la revista y la consolidación de un perfil disidente, precisamente aquel que se suele recordar cuando se habla de ella. Nace con una tirada menor a 40.000 ejemplares mensuales y, para mediados de 1980, las ventas se acercan a los 150.000 ejemplares, repartidos entre dos ediciones quincenales (MATALLANA, 1999, p. 93). Con el comienzo de la década del 80 , incluye nuevos colaboradores y, de resultas del clima imperante con la relativa apertura política promovida por la Junta militar, amplía el rango de su abordaje satírico. Es para este momento que se abre una etapa diferente, de creciente "politización" de la revista -si entendemos esa categoría por el tratamiento de los asuntos políticos con un enfoque "serio", propio de los semanarios de actualidad, y de la mayor acentuación de los formatos humorísticos con intencionalidad similar-.

\section{Humor como un espacio de intercambios y debates}

Un rasgo distintivo de Humor fue el grado de comunicación alcanzado con sus lectores a través de la sección de correspondencia, denominada "Quemá esas cartas". El apartado supo no sólo contener opiniones relativas a la revista, sino para volcar diversas inquietudes e incluso albergar debatir entre lectores. Por su parte, al conceder un espacio significativo en sus páginas a la correspondencia -regulando y seleccionando lo publicable, como es usual en la prensa-, ${ }^{2}$ Humor supo legitimarse mostrándose receptiva de las demandas de su público, mientras obtenía indicios de sus intereses y reacciones frente a los contenidos publicados.

Además de promover el flujo epistolar, Humor estimuló otras formas de participación de su público, como el envío de materiales para su posible publicación. El éxito de su convocatoria puede medirse por el hecho de que una sección que recogía recortes de la prensa con erratas graciosas, "Nada se pierde", fue organizada desde los primeros números con el aporte mayoritario de los lectores.

\footnotetext{
${ }^{2}$ Debe aclararse que existían limitaciones que el criterio editorial imponía para la publicación de la correspondencia enviada por los lectores, y no solo por los riesgos de una censura atenta a publicaciones disidentes como Humor; sino por motivos más rutinarios como el espacio disponible, la representatividad otorgada a determinadas cartas en desmedro de otras o la prioridad dada por la revista al comentario de ciertas temáticas -que incluye el interés editorial de publicar aquellas afirmaciones que no estaba dispuesta a asumir por sí misma-.
} 
En nuestro caso, hemos apuntado a reconstruir los debates llevados adelante en la que hemos definido como etapa inicial de Humor, sobre cuestiones de interés público, cuando comenzaban a vislumbrarse signos de un paulatino relajamiento de la represión estatal. Ya en los años previos al golpe de estado de 1976 existía una retracción de los intercambios públicos por las condiciones impuestas por la "militarización de la política", y luego, por efecto del terrorismo de estado. Se ha definido el periodo dictatorial por la "privatización de la vida cotidiana", de retraimiento forzado de la actividad corriente en los espacios públicos. En un extremo, este comportamiento se confundió con la sensación social de pérdida de códigos y referentes comunes reductores de la incertidumbre. Fue una conducta plausible ante el escenario del terrorismo de estado, uno de cuyos efectos sociales era la difusa advertencia de que su actividad podía alcanzar a cualquier persona, implicada o no en actividades subversivas (O’DONNELL, 1987; CALVEIRO, 2004, p. 147). Sin embargo, la porosidad del control estatal permitió distintas iniciativas que, por su localización o su alcance, denotaron una desconexión o disidencia con las premisas enunciadas por el régimen. Como señala Pilar Calveiro, todo poder con pretensiones totalizadoras no puede evitar ostentar límites a su accionar controlador. Determinados niveles y ámbitos de intervención social escaparon a la mirada oficial, o bien contaron con su tolerancia por su aparente inocuidad, los cuales permitieron múltiples ámbitos de resguardo y recreación paulatina de prácticas desaconsejadas en los momentos más duros de la represión militar. No estamos hablando necesariamente de actividades encuadrables en una oposición, parcial o sistemática al orden imperante, sino a prácticas corrientes variadas -la asistencia a reuniones, la frecuentación de ciertos lugares públicos, determinados consumos culturales son ejemplos-.

En este último plano se ubica Humor y se verifica inscrita la demanda de una parte de sus lectores, mediante el ejercicio epistolar. No obstante, la revista en sí misma tampoco fue ajena al espíritu crítico de aquellos: el comentario y debate de los contenidos y recursos formales de Humor llegó, en casos extremos, a obligar a la revista a salir en defensa explícita de los valores del proyecto editorial. Observar los casos en que estas polémicas se llevaron adelante, resulta provechoso, por cuanto condensan puntos de observación para aprehender cosmovisiones en juego dinámico entre autores y lectores.

¿Por qué observar estos intercambios polémicos en una revista humorística? Una publicación como Humor, durante el periodo estudiado, asociada al entretenimiento ostentó una capacidad significativa de generar y condensar sentidos en danza sobre distintos fenómenos sociales, vedados para otros medios y discursos "serios". Humor, en sus interrelaciones con el público lector, con la repercusión de sus contenidos desde instituciones de la sociedad civil y desde otras publicaciones, también habla de un clima de ideas de la época, susceptible de ser observado en la porción del ingente tráfico epistolar seleccionado para su publicación en la revista.

La revisión del corpus planteado permite distinguir tres debates notorios, con participación de los lectores. El primero de ellos, ubicado en los números iniciales de la revista, 
tematiza la calidad cultural del rock y su posible carácter renovador en la música argentina. Centrado alrededor de la música como objeto del gusto individual, escapa a nuestros propósitos abordarlo por cuanto es llevado adelante entre los lectores y no compromete directamente a la revista. ${ }^{3}$

De los otros intercambios polémicos considerados, uno aborda la posibilidad y validez ética de abordar el genocidio judío mediante el humor gráfico. El otro tomó forma en torno a la representación de las clases populares en la historieta "Romancero ilustrado del Eustaquio". En ambos se evidencia una participación reiterada activa del lectorado e intervenciones editoriales significativas, constituyendo situaciones oportunas para entender tanto el funcionamiento de la sección de correspondencia como el contraste entre los criterios sostenidos por Humor y los de su público.

\section{La Shoah en chistes}

La revista publica, en su número 21, de fines de 1979, una serie de chistes gráficos realizados por el dibujante Catón. (Humor 25, octubre de 1979, p. 60-61) Son siete en total, e intentan una aproximación humorística del genocidio judío -o Shoah, de acuerdo a la denominación hebraica-. Para ello, presentan situaciones ubicadas en campos de concentración, protagonizadas por oficiales y soldados nazis y prisioneros judíos.

Cada personaje es compuesto desde la caricatura, esto es, por la reproducción de determinados rasgos socialmente estereotipados, asociables al sujeto en particular o al o a los colectivos a que pertenece (CARBONE, 2007, p. 156). Los individuos judíos se caracterizan por poseer la nariz curva, el cabello enrulado y, con frecuencia, utilizar anteojos. Al mismo tiempo, portan las marcas del carácter "judío en campo de concentración", al vestir un uniforme de prisionero y ostentar el número de registro tatuado en el brazo. Los captores, por contraste, responden al estereotipo atribuido a la "raza aria" y el nazismo: nariz recta, cabello lacio, uniformes con símbolos de las SS - la sigla aparece en los cascos, junto a la calavera cruzada con tibias en las gorras-, llevan el brazalete con la esvástica, están armados de pistolas, látigos, etc. Completa el cuadro una actitud cínica y deshumanizadora hacia sus víctimas judías. Por consiguiente, la representación visual compartida por todos los chistes resulta eficaz para que el

\footnotetext{
${ }^{3}$ Debate desarrollado en los números 7, de diciembre de 1978, 9 de febrero de 1979 (donde la revista declara que "no hay que tener miedo a la controversia") y el 10 de marzo de 1979, en el cual la discusión se combina y deriva con los comentarios surgidos a partir de una nota de Alejandro Dolina acerca de la juventud. Surge a raíz de una sugerencia de un lector para que Alicia Gallotti entrevistara al por entonces integrante del grupo Serú Giran, Charly García. Existe un cuarto debate registrable, a raíz de la modificación de las incumbencias profesionales de la carrera de psicología por el ministerio de educación. Tampoco lo hemos considerado por tratarse de una controversia externa a los contenidos de la revista. Humor $n^{\circ} 43$, septiembre de 1980.
} 
lector despeje cualquier ambigüedad interpretativa, recreando el escenario emblemático de los campos de concentración.

Las situaciones mostradas transcurren en un campo de concentración, igualmente compuesto por elementos que los identifican o están relacionados, tales como el tren de prisioneros, los hornos crematorios o la insinuación de las ejecuciones mediante la representación de calaveras humanas con el tiro de gracia. En consonancia, se alude en cada chiste a varios procedimientos de la acción genocida, volviendo objetos satíricos situaciones tales como el proceso de identificación de los reclusos, los fusilamientos con aplicación del tiro de gracia, la privación de alimentos y la cremación en los hornos de los campos.

Dos de los chistes reponen tópicos, más tarde señalados como prototípicos de la perversidad nazi: la utilización de la piel de los judíos asesinados para encuadernaciones y la conversión de sus cuerpos de los asesinados en materia prima para fabricar jabón. En ambos, la comicidad buscada surge del diálogo entre dos militares nazis respecto a sus cautivos judíos, como efecto de un desenlace inesperado que alivia la tensión de la escena a los ojos del lector:

¡Basta de latigazos, Sargento! [Se refiere al tormento a un prisionero] ¡Después me quedan todas las encuadernaciones marcadas!"

“iA ver, Sargento!, ¡Búsqueme setenta músicos! Nos pidieron una partida de jabón de tocador [...] (Humor, n. 43, 1980).

Las reacciones del lectorado ante esta publicación no se hicieron esperar. En los tres números posteriores de Humor salen publicadas en "Quemá esas cartas" numerosas misivas (son 22 en total), ocupando gran parte de la sección de correspondencia. Para el número 25, se consigna que se seguían recibiendo cartas sobre el tema, pero que el debate "no [ib]a más" y no se publicarían en lo sucesivo.(Humor, dic., 1979, p. 14).

La carta que abre el debate es la firmada por Nehemías Resnitzky y por Daniel Levy, presidente y secretario de la DAIA, respectivamente. La Delegación de Asociaciones Israelitas Argentinas era en aquel momento -y sigue siendo- una de las instituciones representativas de la comunidad judía. En ella, los autores expresaban su "profunda consternación", condenando "esa macabra complacencia de la revista con el mayor crimen de la historia contemporánea". Concluían calificando a la producción gráfica en cuestión como "esa humillante explosión de odio antisemita." (Humor, 1979, p. 12). En el número posterior de la revista se publicaron otras dos cartas de instituciones judías, del Ente Coordinador Sefaradí Argentino (ECSA) y del secretariado de la Confederación Juvenil Judeo Argentina. Los titulares de la primera remarcaban su indignación y su protesta; la CJJA -sin rúbricas personales-, dejaba sentado su repudio y requería que "en lo sucesivo, no preste[n] las páginas de la revista de su dirección a elementos ajenos al sentir del pueblo argentino." (Humor, 1979, p. 12). 
El tono de las cartas responde al patrón de la denuncia pública como forma de divulgación de una injusticia, a partir de un incidente puntual. No se detiene en la muestra del acto injusto, sino que apunta a apoyarse en el peso de la opinión para obtener una reparación que se relaciona, más que con lo legal, con una rehabilitación de la víctima injustamente acusada y la condena moral del victimario (BOLTANSKI, 2000, p. 238). Por esto es que las cartas aluden al "más horrible genocidio del siglo XX", acontecimiento que excede lo sucedido a la comunidad judía, para proyectarse a la humanidad en su conjunto.

El planteo reparatorio cede lugar al repudio en las cartas de las entidades judías, muy similares en su contenido, y sólo se exige a la revista la exclusión ya apuntada. Es en algunas misivas de lectores individuales donde aparecen las exigencias de rectificación, motivadas por su valoración de la revista y el interés de seguir leyéndola pese a este incidente desafortunado. Así, un lector que se presenta como "amigo de la revista" lamenta la publicación de los chistes, viéndola como una equivocación del autor y de la revista (Carta 1, Humor, n. 22, p. 12-13).

Dada la repercusión negativa de los chistes, Humor ubica la correspondencia sobre la cuestión en las páginas iniciales de "Quemá esas cartas", que otorgan mayor visibilidad a las cartas publicadas; las misivas de contenidos más variados son relegadas a "vuelta de página". El criterio editorial sobre el tema encabeza el apartado de correo durante los números que abarcan la polémica. Allí siempre aparece un texto sin firma antecediendo la correspondencia, con el fin de anticipar los términos desde los cuales, a juicio de la revista, debiera leerse la publicada y responder de manera puntual a algunas objeciones. El título "Holocausto I", en referencia a los chistes, domina cada entrega, para circunscribir el espacio de publicación de misivas sobre el tema dentro de la sección. Se elige al respecto comenzar su "defensa" por la mención a la DAIA y canalizar a partir de sus planteos la estructura del texto. (Humor, n. 22, p. 12).

La revista reconoce la importancia institucional de los organismos comunitarios y, por ende, admite la legitimidad de su reacción ante los chistes, lo que decide a su dirección a responderles con "seriedad". En este sentido, el texto editorial subsiguiente asume que lo cuestionado implica la razón de ser misma de la publicación: "No tenemos más remedio que ponernos serios para dejar claramente establecidas las pautas que rigen el humor de nuestra revista".

El texto continúa postulando que el humor es una forma de la crítica, dependiente "de la calidad de quienes lo practican, pero nunca de los terrenos que invade", por lo que "no debe retroceder ante los temas espinosos". Esta "ética de la calidad" postulada por Humor entre los valores de su contrato de lectura, habilitaría entonces el tratamiento de temas controversiales con pretensión de sensatez. Frente a las críticas, arguye sobre el profesionalismo de los autores, en tanto enuncia las normas éticas seguidas por la revista. Esta ética profesional se basa, para Humor, en la autonomía temática y estilística de cada colaborador, solo limitable por las barreras morales y estéticas "normales" (sic) para la expresión escrita. Desde este punto, la revista 
reivindica la validez del género humorístico para tratar cuestiones delicadas, con independencia del efecto eventual que sus productos tuvieran en los lectores.

Otra operación defensiva de Humor apunta a ubicar los chistes de Catón dentro el campo reconocido del "humor negro". La remisión a la figura del narrador y periodista estadounidense Ambrose Bierce, catalogado como maestro de esta vertiente humorística, refuerza la justificación por la vía de lo convencional y la autoridad canónica legitimante.

Para la revista esta veta discursiva, además, se justificaba porque permitía evidenciar la hipocresía de la moral media de la sociedad. Previamente, una colaboradora importante durante el primer año de Humor, Alicia Gallotti, había advertido que "aquellos que se horrorizan del juego abierto, suelen ser maestros en el arte del juego cerrado", dando a entender un doble estándar moral que eludía el humor sobre temas espinosos a la luz pública pero lo alentaba en privado.

Posturas como la de Gallotti permiten fundamentar el carácter crítico y no agraviante que a tenor de la revista podía adivinarse en los chistes. Que no eran, en palabras del texto editorial, "un ataque a los judíos", sino un recordatorio de su genocidio por la vía de la incorrección política. La revista intentaría, pues, mostrar el "juego abierto", respecto a un horror que quizás habría encontrado otra forma plausible de mostrarse, mediante su representación cómica. Pues, para Humor los chistes desnudan la perversión nazi, antes que la justifican. Ellos no serían otra cosa que "una flagrante crítica al nazismo y sus métodos genocidas" (Humor, 1979, p. 12). Desde esta postura, relega todo desagrado a una cuestión de gustos, en donde lo inapropiado se deja al criterio personal del lector. La discusión se desplaza de lo ético a lo estético, del terreno de determinados valores socialmente defendibles al campo de lo opinable, subjetivo y contingente.

La posición de la revista al reivindicar, con matices, los chistes, se podría enunciar como irónica, por pretender un distanciamiento esclarecedor. Como afirma Henri Lefebvre (1967, p. 452),

[...] el irónico desempeña una comedia: la del no saber y del falso conocimiento. Tiene un papel. Lleva una máscara. Y esta es su manera de desenmascarar los papeles. Dice lo falso (y que él sabe falso) para llegar a lo cierto. Asume el papel de su alienación para desalienarse y desalienar a los otros. Asume su mal papel y finge si es necesario la mala fe, superándola por el fingimiento y superando al mismo tiempo la grosera simplicidad fingida o real, la de la buena consciencia.

Antes que una burla de la Shoah, los chistes devuelven el horror al presente como advertencia, bajo la forma de chanza. Asimismo, el texto editorial de Humor condena acontecimientos heterogéneos pero calificados de genocidios como los de Auschwitz, Hiroshima, 
la Camboya del Khmer Rojo, la masacre de My Lai y otras (Humor, 1979, p.12). Cualquier anclaje con la situación argentina está ausente; los referentes posibles están emplazados en lugares lejanos por geografía y ubicación histórica. Ese parece ser el límite político -en tanto problematización de cuestiones públicas- evidenciado por Humor en la polémica.

Ahora bien, la revista de Cascioli debió hacer frente no solo a las entidades, sino que recibe la atención de otros medios relacionados también con el ambiente comunitario. Dos periódicos, Nueva Presencia y Mundo Israelita son mencionados en un nuevo acápite de "Quemá esas cartas" del número siguiente a la publicación de los chistes, el 23 (Humor, 1979; Nueva Presencia, 1979). Mundo Israelita había publicado una pequeña nota denominada "Ante un grosero agravio" en sus páginas interiores. En ella repudió el "grosero acento antisemita" de los chistes y, en lo sustancial, reprodujo la carta de la dirigencia de la DAIA a Humor (Mundo Israelita, 1979, p. 2).

Por contraste, Nueva Presencia le dio mayor trascendencia al tema. Vinculado con sectores progresistas de la comunidad judía, más tarde cercano al movimiento de derechos humanos y la denuncia velada de los crímenes de la dictadura -su director sería fundador del Movimiento Judío por los Derechos Humanos en 1982-, se había referido críticamente en su nota de portada a los chistes. Su tono, diferente al sentado por las autoridades de la DAIA, recurre a la mención a la obra de dos escritores, Sergio Tarnopolsky y Juan José Sebreli, para definir a los "prejuiciados de buena conciencia" (título, por otra parte, de un ensayo de Tarnopolsky retomado para la nota de Nueva Presencia). De acuerdo a la lectura de Nueva Presencia, estos "prejuiciados", pese a ser "bienpensantes" (sic), revelarían en momentos de crisis su intolerancia mediante prejuicios antisemitas. Humor se ubicaría dentro de ese grupo. Entre los cuestionamientos por la representación humorística del genocidio judío, Nueva Presencia desliza cierto estupor por la actitud de una revista "habitualmente elaborada con inteligencia y rigor por reconocidos caricaturistas", que "a veces insinúa un humor de avanzada y cuyos integrantes podrían ser encasillados bajo el rótulo común de 'liberales', en el sentido más amplio de la expresión”.

Sin embargo, la volanta que acompaña el título identifica a Nueva Presencia con los valores originarios adjudicados a Humor: "En épocas de crisis también los demócratas pueden caer en la intolerancia". Su reconocimiento de que Humor es parte de los sectores "demócratas", respetuosos de las libertades y derechos de la sociedad, lleva a pensar que Nueva Presencia la respetaba y la ubicaba probablemente en un plano ideológico compartido respecto a los valores mencionados. El semanario comunitario, a continuación, relacionaba el desacierto de Humor con los debates promovidos por la prensa a partir del secuestro, cautiverio clandestino y posterior expulsión del periodista judío Jacobo Timerman. Sospechado por la dictadura de tener relación con capitales provistos por la organización político-militar Montoneros, a través del llamado "grupo Graiver", Timerman fue secuestrado por un grupo de tareas en abril del 1977, mantenido clandestinamente en cautiverio y torturado, además de ser despojado de la propiedad de su diario, La Opinión. Meses después, por la presión internacional, fue encarcelado de manera pública. En septiembre de 1979 Timerman fue liberado, despojado de su ciudadanía y expulsado del país. 
El periódico comunitario había seguido el tema como parte de lo que enunciaba como un clima de antisemitismo atizado por algunos medios de comunicación. Como se reitera en su juicio de los chistes de Humor, el trasfondo de la agitación mediática apuntaba, para Nueva Presencia, al tópico de la asimilación exitosa o fallida de la comunidad judía al resto de la ciudadanía argentina.

Buena parte de la correspondencia implicada en la controversia permite aseverar que la conjetura de Nueva Presencia era correcta. La sucesión de los números de Humor había ido sumando argumentos que desbordaban la temática de la representación de la Shoah. El inicial está dominado por las cartas de denuncia de las entidades comunitarias y se incluyen las del mismo tono enviadas a título individual, la mayoría de las cuales pertenecía a lectores que se reivindicaban de confesión judía. A partir del segundo número, el intercambio comienza a focalizarse exclusivamente en las heterogéneas reacciones de los lectores individuales, no solo ya ante los chistes, sino asimismo ante las cartas de las entidades y entre sí. Allí aparece, como en los medios de la época, la cuestión de la legitimidad de la doble pertenencia ciudadana-confesional.

Si los titulares de la DAIA y los del ECSA se habían definido en sus esquelas de reclamo como "argentinos y judíos", junto a varios lectores, otra parte del público ve esa definición como una incongruencia, y reclama por la aparente pretensión comunitaria de ostentar una doble nacionalidad. Además, algunos de ellos controvierten el postulado de la excepcionalidad de la Shoah como genocidio, algo que las instituciones comunitarias o los lectores que condenaban los chistes no destacaban en sus cartas, pero que desprendían del énfasis puesto en la denuncia. El reclamo de las entidades y lectores afines, para estos lectores, se limitaría a una reivindicación sectorial desatenta a otros dramas similares. Varias otras cartas, en especial las agrupadas en el último número de la revista que concluye la polémica, coinciden en reivindicar abiertamente a Humor como un espacio pluralista, en el que situaciones como las del genocidio judío podían ser tematizados sin privilegios. Al menos desde el humor negro que, como arguye una lectora en consonancia con la revista, es materia de las decisiones de lectura de cada quien.

Las misivas de este tenor entrañan, de hecho, una defensa del pluralismo algo extraña a los ojos actuales, en un marco que, además de las vicisitudes del maltrato -clandestino y públicoa Timerman, contemplaba la entonces reciente visita de la Comisión Interamericana de Derechos Humanos de la OEA para investigar las numerosas denuncias por las violaciones de derechos humanos. Este evento, cubierto por la prensa pese a las intenciones en contrario de la junta militar, aportaría a resquebrajar el silencio impuesto, pero especialmente a impulsar a posicionarse a distintas franjas políticas y sociales (GORINI, 2006, p. 334). El informe producido por la Comisión confirmaría el trato agravado a los detenidos-desaparecidos de confesión judía. Sin embargo, ni los lectores críticos de la supuesta parcialidad de las entidades judías ni estas vinculaban sus textos con la coyuntura de manera explícita. Humor, por su parte, como se expuso, basó la defensa de Catón en el carácter ejemplar de los chistes como denuncia satírica del 
nazismo y, por extensión de todos los "ejemplos ilustrativos de la bestialidad humana..." (Humor, 1979, p.12).

Es Nueva Presencia quien intenta una disrupción respecto al discurso mesurado de las entidades. Coincide en evitar las comparaciones pero, en cambio, repolitiza la Shoah en el plano de su presente, avanzando hacia donde Humor parece precaverse. Además de la mención del caso Timerman, una sugestiva afirmación del periódico cuestionaba el núcleo del argumento de Humor sobre el albedrío del humorista:

¿Será su impotencia y su miedo a publicar chistes antigubernamentales lo que los lleva a cortar el hilo por lo más delgado? ¿No será, pues, que los muertos lejanos son más saludables que los cercanos?4

Con la alusión a aquellos "muertos cercanos", a nuestro entender, el periódico judío intenta sugerir un paralelismo entre los asesinados en el genocidio judío y las víctimas del terrorismo de estado argentino. La recriminación de Nueva Presencia a Humor, además de señalarle su responsabilidad, remarca con crudeza su falta de decisión a la hora de abordar un presente conflictivo. Esta alusión, a nuestro entender, compone una de las partes con las que el periódico judío construye el paralelismo entre los asesinados en la Shoah y las víctimas del terrorismo de estado argentino. Nueva Presencia repudia el escarnio contenido en las viñetas de Catón como un error político, que repite y contribuye al acrecentamiento de los prejuicios antisemitas en la sociedad, de los que los "prejuiciados" son siempre difusores potenciales.

Solo puede ser objeto de presunciones el que Humor, en una etapa histórica en que la censura y los grupos represivos paraestatales seguían en vigencia operativa, intentara denunciar la situación política argentina sugiriendo una conexión entre el genocidio judío y terrorismo de estado a través de chistes como los de Catón. Nueva Presencia, inmersa por su raigambre con mayor fuerza en la lógica conflictiva del contexto, llega a sostener lo contrario. Lo cierto es que el intercambio de opiniones en "Quemá esas cartas" muestra reacciones que- van llevando la polémica hacia un terreno en el que Humor ya no discute, acaso porque prefirió mantenerse en los límites de lo que entiende, es su "incumbencia específica": el humor y su ética profesional.

\section{El Eustaquio (y sus lectores), ante los riesgos del suburbio}

\footnotetext{
${ }^{4}$ Nueva Presencia, Meses después y desde su exilio, Timerman acusaba al régimen argentino de "actuar como la Alemania nazi, practicando con respecto de los judíos una política de exterminio, y culpaba a la DAIA por ignorar la amenaza de un nuevo Holocausto." (BARROMI, 1995, p. 341). Dichos situados hacia 1980.
} 
Uno de los aspectos más destacados de la revista Humor es su contribución a la renovación del costumbrismo como tematización de la vida cotidiana desde el punto de vista del humor gráfico y escrito. En ella el sujeto representado excluyente pertenece a las clases medias metropolitanas. Son, por el contrario, escasas las ocasiones en que aparecen tematizados sujetos de las clases populares. Cuando están presentes, ocupan invariablemente un lugar lateral en la trama como partenaires de los anteriores y ejercen oficios urbanos menos calificados: son peones, albañiles, quiosqueros, porteros, etc. La obra gráfica y escrita de distintos colaboradores de la revista, como Grondona White, Ceo, Cilencio, Tabaré, Fabre y Kalondi, entre otros, reitera esa orientación representativa.

Sin embargo, es una historieta de Fabre y Tabaré ${ }^{5}$ denominada "El Romancero ilustrado del Eustaquio", la que rompe con esta tendencia. Esta tira supone uno los escasos ejemplos de representación (costumbrista) de las clases populares en la revista Humor en sus años iniciales. El que sea parte de nuestra investigación devino de la repercusión entre los lectores de la revista, en cuanto impulsó un debate en "Quemá esas cartas" sobre los modos de entender lo popular y de relacionarse con una de sus figuras estigmatizadas, la del "cabecita negra". Lo hizo en un tiempo en que toda posibilidad de discusión pública sobre lo subalterno estaba vedada, tras haber sido dicha condición un estandarte de la movilización política previa al golpe de estado.

De la sociedad creativa entre Fabre y Tabaré surgieron varias tiras que exploran caracteres marginales, tanto por ubicarse en las zonas periféricas como por su indigencia material o su desajuste respecto a los valores sociales predominantes. La tira del "Romancero ilustrado del Eustaquio", dentro de ese terreno, muestra una figura subalterna entendida no solo por su condición material, pasiva, sino por la posesión de determinadas capacidades para desenvolverse, sobrevivir, e imponer su localía.

La historieta surge con base en unas breves fábulas satíricas de Fabre publicadas en "Nada se pierde". Con su conversión al formato gráfico, mantienen la misma estructura narrativa a través de sucesivos episodios: el paseo extraviado de un personaje, el Eustaquio, por parajes de la ciudad de Buenos Aires o -más frecuentemente- del conurbano bonaerense, de madrugada y en noches oscuras, para encontrarse de repente con un personaje de aspecto estremecedor, que lo interpela. Insatisfecho por la respuesta del paseante, su contraparte lo conmina a cumplir determinado requisito cuyo desarrollo no se muestra, en tanto el recurso elíptico apela a la imaginación del lector y fuerza el desenlace cómico. La conclusión gráfica reiterada de la historieta, nos indica que culmina violando al Eustaquio.

\footnotetext{
${ }^{5}$ El primero, alias de Eduardo Fabregat, secretario de redacción de Humor; el segundo, seudónimo de Tabaré Gómez Laborde, dibujante uruguayo con una vasta obra iniciada en dicho país y proseguida en Argentina en medios como el diario Noticias, Satiricón, Mengano, Chaupinela y Tía Vicenta, entre otros. Es conocido por la tira "Diógenes y el linyera", publicada ininterrumpidamente en Clarín, desde 1975.
} 
Distintas estrategias de la composición gráfica y de los diálogos alientan la comicidad en el lector, dándole indicios para comprender el destino final del desorientado citadino. La composición gráfica de los personajes enfrenta a un pequeño habitante de la urbe, con la vestimenta y modales educados de las clases acomodadas, a un individuo grotesco, denominado "negrazo". Este es un individuo de tez oscura, pelo enrulado o "motoso", desaseado, vestido con ropa rota y de proporciones corporales gigantescas. Para peor, libidinoso, taimado y falto de todo recato. En suma, un ser embrutecido y animalizado. Por su parte, los diálogos potencian la dialéctica de estereotipos entre las buenas maneras del "civilizado" y la astucia del "negrazo".

El cariz cómico del relato no esconde un sentido de extrañamiento embarazoso. Constituye, desde este punto de vista, una escena suscitadora de una risa nerviosa. Como se sabe, Freud ha definido lo siniestro como algo familiar a la vida psíquica que se tornó extraño por su represión (FREUD, 1973, p. 42). Si, por un lado, la desmesura abyecta del "negrazo" mueve a comicidad, su aparición inesperada -la de su deformidad, el del otro orden implicado distinto al "normal", nuestro-, que el lector acompaña en la sorpresa del Eustaquio en cada nuevo episodio, provoca perplejidad. Este recurso cobra eficacia con la repetición, que "nos hace parecer siniestro lo que en otras circunstancias sería inocente, imponiéndonos la idea de lo nefasto, de lo ineludible, donde en otro caso solo habríamos hablado de "casualidad'" (FREUD, 1973, p. 36). Los lectores experimentan la comicidad junto al desafío de confrontarse a una cotidianeidad habitual que los sorprende y los inquieta. Vale recordar aquí la concepción freudiana sobre el humor, que lo define como una respuesta del sujeto ante la evidencia del dolor. La salida humorística conjura la gravedad de la amenaza y la relativiza, aunque sea por un momento.

En definitiva, la sonrisa del lector adviene de comprobar en las acciones del Eustaquio la transgresión del orden establecido, que prescribe de manera implícita que algunas zonas no deben traspasarse - $y$ algunos cuerpos no deben mezclarse-, so pena de un castigo severo y aleccionador. La historia mantiene implícito un sentido normativo, aleccionador -e ideológico-, sobre las consecuencias nefastas de meterse donde no se debe.

Desde el plano literario, puede establecerse un parentesco entre el "Romancero (ilustrado) del Eustaquio" con el cuento "El matadero". Este texto de Esteban Echeverría, escrito alrededor de 1838-40, durante el gobierno de $\operatorname{Rosas}^{6}$ y publicado póstumamente, compone el canon fundacional de la moderna literatura argentina. Contempla el encuentro casi accidental entre un joven unitario letrado y sectores plebeyos agrupados en torno al matadero, que adquirirá un carácter trágico. No hay posibilidad de comprensión mutua y el desenlace de la historia acaba con la muerte del joven, que metaforiza para Echeverría la suerte de los sectores ilustrados del país durante el periodo. El "Romancero..." puede verse como una recreación paródica del cuento de Echeverría, puesto que el cambio de escenario, tiempo histórico y de personajes constituye un ${ }^{6}$ El brigadier Juan Manuel de Rosas fue gobernador desde 1829 de la provincia de Buenos Aires y desde 1835 a 1852 , titular
de la Confederación Argentina, opuesta a las fuerzas políticas y militares conocidas como "Partido Unitario". 
desvío de la narración originaria, la cual puede reconocerse todavía en el cruce del culto Eustaquio y el "negrazo" lumpen.

Pero, asimismo, la caricatura del "negrazo" delineada por Tabaré remite al imaginario del "cabecita negra", figura que resume el estereotipo dominante del individuo popular, visto como un ser rodeado de abyección. Así como los matarifes del cuento echevarriano condensan para la literatura de la época el paradigma de la "barbarie", el "cabecita negra", desde el punto de vista de las clases poseedoras, es el tipo ideal -en sentido weberiano- del otro que amenaza la ciudad desde sus suburbios marginales. Tal denominación le cupo a los migrantes internos provenientes en especial de las provincias del norte, en razón de la crisis de la actividad agrícola y las posibilidades laborales abiertas por el incipiente desarrollo industrial metropolitano. Su tez trigueña y el color renegrido de sus cabellos los asemejaba, a los ojos de los blancos porteños, al "cabecita negra", un ave del lugar. Con el crecimiento poblacional y la falta de viviendas, los nuevos pobladores se agruparon en lo que se conocería como "villas de emergencia". Su asentamiento permanente hizo que fueran rebautizadas, más tarde, como "villas miseria", ganando un mote despreciativo adicional, el de "villeros" (GUBER, 1984, p. 83).

En tal sentido, la historieta de Fabre y Tabaré evoca, de modo cómico, esa presencia inevitable pero negada, recluida al nivel de lo ominoso, de la experiencia urbana. El hecho de que la dictadura intentara erradicar parte de las "villas miseria" (OZSLAK, 1982, p. 185) e invisibilizar a los subalternos, resalta los méritos contemporáneos de "El romancero ilustrado del Eustaquio". Al talento de los autores para plasmar una tira eficaz en su trama y efectiva en su representación gráfica, se añade su capacidad para suscitar problemáticas que van más allá de lo ficcional (o que encuentran en lo ficcional una manera elocuente de ser invocadas), con independencia de las intenciones que persiguieran.

Sobre dicha capacidad se entabla en Humor un nuevo debate, desencadenado por la carta de una lectora (Humor, 1980, p.16). Su importancia radica, al igual que en el caso anteriormente analizado, en cuestionar las "políticas del humor" de la revista y fomentar sus aclaraciones, en un contexto donde esa discusión aparecía como inconveniente. Pero, con más énfasis en este caso, por suscitar variadas posturas de los lectores frente a esa vinculación entre el ejercicio humorístico, sus referentes y la vida cotidiana.

La autora de la carta juzga, en síntesis, que la historieta del "Romancero..." es racista. Califica al Eustaquio como un émulo del Ku-Klux-Klan y al "negrazo" como un "violador y homosexual" (sic). No obstante la dureza del juicio, admite que el sesgo racista puede deberse a motivaciones inconscientes, arraigadas en la sociedad, que los autores reflejan más allá de su voluntad. Desde esa perspectiva, elabora un discurso crítico que apela a saberes expertos relacionados con la Humanidades. Su carta arguye sobre los orígenes de los prejuicios raciales y sobre la vigencia que mantienen en la conformación de las identidades e imaginarios sociales racistas. En sus planteos se sirve de la obra del psiquiatra y militante antiimperialista Frantz 
Fanon, referencia poco esperable en el marco dictatorial, pero admisible al presentarlo, despojado de toda referencia política, como una autoridad profesional. Mediante citas textuales de Fanon, la autora parangona la estigmatización del negro en Occidente a la operada sobre los "cabecitas negras" en América Latina. Toda "sociedad enferma", dice nuestra autora, se sirve de esa construcción ideológica para legitimar la explotación negra a manos de los blancos, representantes de la cultura civilizada.

Humor ante estos planteos vuelve a ejercer la defensa de sus colaboradores. Apela a la ironía para contestar a la lectora y descalifica lo que observa como un forzamiento interpretativo de la historieta de Fabre y Tabaré. Reitera, como lo hiciera respecto a los chistes de Catón, su apuesta al humor como desenmascaramiento crítico de lo que otros toman en su literalidad. Es significativo que Humor publique, pocas semanas después de la polémica, un texto que acusa de racista la publicidad de un espectáculo africano a estrenarse en Buenos Aires (Humor, 1980, p. 10) La gravedad editorial de su tono no impide advertir que, abordando el racismo hacia el tipo étnico africano, elude la discusión de las identidades étnicas y las connotaciones que definen al "crisol de razas" argentino. Para la revista, el racismo queda confinado a ser un "problema afro"; los llamados "cabecitas negras" permanecen invisibilizados e indecibles -al menos durante el periodo estudiado- en el discurso editorial "serio" de Humor.

El lectorado muestra su apoyo unánime a la revista, de acuerdo a la correspondencia publicada, y relativiza las críticas al "Romancero...". Sus planteos reivindican el carácter autónomo de cualquier función (o huella) social del humor en tanto es ejercido por profesionales en la materia:

\footnotetext{
Una señora (o señorita) que cita frases de psicoanalistas negros y plantea un problema social que nada tiene que ver con la historieta a que se refiere. [...] Pienso que nadie puede hacer una análisis tan ridículo de una tira original y graciosa como 'Eustaquio' y pretender que se le tome en serio. (Humor, 1980, p. 36).
}

La anterior es una de varias misivas que le reivindican la potestad del humorista para expresarse desde lo que entienden que es su lenguaje específico, la sátira y el humor. Un segundo lector ejercita una exégesis sarcástica de cada argumento de la carta crítica del "Romancero...". Ante el tópico fanoniano que indica la asimilación del color con la suciedad y la inferioridad psíquica para justificar la explotación blanca, nuestro lector responde que:

En fin, todos los que por distintos motivos, sociales, étnicos, culturales, climáticos y de suerte, no tienen un bidet y una ducha a 
mano huelen fatalmente a 'penetrante hedor de dudongo en celo', y eso segrega segregación.” (Humor, 1980, p.17).7

Le sigue la cita de un verso del clásico gauchesco de José Hernández, el Martín Fierro, donde se deplora el desaseo de "esos indios vagabundos [...] viven lo mismo quel cerdo, en esos toldos inmundos" (sic), seguido de un “¿viste?” dirigido a la lectora. Por consiguiente, los planteos sobre la discriminación racial los rebate este lector reafirmando la exclusión de quienes, entre otros aspectos, no respetan las convenciones occidentales sobre la limpieza; y apoya su certeza en la referencia escolar del Martín Fierro, citada para interpelar a la lectora y convencerla de que lo dicho es evidente (“¿viste?”), porque lo dice la autoridad de la tradición y de un sentido común que informa sus concepciones. En su comentario a esta carta, Humor desliza una diferencia sólo perceptible para aquellos lectores compenetrados con la obra de Hernández. Puesto que incluye de manera anónima otro verso del Martín Fierro, que define como racista:

El racismo es una lacra desembozada, que no suele esconderse detrás de divertimentos como el 'Eustaquio', pero en cambio aparece, esplendorosa [...], en aquel verso que dice: 'A los blancos hizo Dios/con barro de limpio huerto/A los negros Lucifer/con tizones del Infierno' (VÁZQUEZ, 1987).

De este modo encubierto, así como defiende el carácter de "divertimento" (sic) del "Romancero...", la revista estaría desconociendo la legitimidad del autor de la carta para tratar la cuestión.

En el límite de dicha interpretación compartida, uno de los autores epistolares supo celebrar en la saga del "Romancero..." la estigmatización ficcionalizada de los subalternos, reivindicando la exclusión social fáctica marcada por los valores dominantes. Reseña en su carta su viaje ferroviario cotidiano, desde la estación metropolitana de Plaza Once de Septiembre hacia su destino suburbano, ocasión que afirma antonomástica para caracterizar a los "negrazos", con quienes comparte su periplo. El relato, en suma, remarca el padecimiento por las incomodidades, la ausencia de decoro, de buenos modales y de higiene de los citados personajes. Por momentos, la descripción vuelve lo actitudinal una marca étnica e indica con ironía cómo ciertas costumbres de los que llama "morochos" van contra los usos de cortesía admisibles. Quien escribe marca en su relato una separación entre este grupo social y el propio (que no escucha en viaje "radios y

\footnotetext{
${ }^{7}$ En apariencia, la opinión del firmante es "calificada", ya que su nombre - Carlos H. Ciencia- coincide con el de un antiguo colaborador de la revista humorística Tía Vicenta, luego editor de la menos conocida Abuelo Barbudo, cuyo seudónimo era 100-cia. (VÁZQUEZ, 1987, p. 291-295).
} 
grabadores en funcionamiento con música de Palito o reportajes a Galíndez y Monzón", sino que pretende aprovecharlo para "leer el diario, la revista Humor o estudiar" ${ }^{8}$ ).

En esta, a diferencia del resto de las cartas, aparece el tipo del "cabecita negra", descendiente de indígenas. Es la única misiva que polemiza abiertamente con la que inicia la controversia, considerando como problema público la existencia de aquel otro, pese a no autorizarse en bibliografías académicas, sino en el sentido común, al igual que aquellos lectores que, como vimos, descartan cualquier relación entre la ficción del cómic y las problemáticas sociales. Decimos que la figura del "cabecita" es una construcción por contraste del sentido común dominante, por cuanto comporta "una potente imagen de acciones, prácticas y trayectorias, ofensivas e inaceptables para aquellos individuos que gozan de una posición social de mayor jerarquía."(TEVIK, 2006, p. 82). Pero no se es un "negrazo" solo por ostentar ciertas actitudes, aunque se pueda ser acusado de tal por compartirlas momentáneamente ("cosa de negros" $"$ ) y esto denote una aparente transversalidad simbólica de la categoría. Sino que el prototipo del "negrazo" real combina actitudes y rasgos morfológicos. Como detalla el lector en cuestión: “Alto, fornido, tez marrón, cabello hirsuto, nariz chata y grandota, aspecto de eslabón perdido" (Humor, 1980, p. 17-18).

El "negrazo" es censurado por permitirle hacer sus necesidades a su pequeña hija en el pasadizo intermedio entre vagones; nuestro lector, entre otras conclusiones, afirma que aquel consiente dicho acto como índice de su condición:

“ $\left.3^{\circ}\right)$ Para que se dieran cuenta [los demás pasajeros] de que era un negro”

Expone, asimismo, su deseo de "borrar a los negrazos del planeta" ante quienes, según cavila, solo pretenden "borrarlos" del territorio argentino. La fuerza cómica de la pintura grotesca de los "negrazos", imitada a la usanza de Humor, pierde aquí el impulso ambivalente de las caricaturas para volcarse hacia lo siniestro, hacia la presencia de una alteridad real, sabida pero indeseable. La ironía cede paso a una descripción descarnada que recuerda concepciones discriminatorias. Esta carta, por ello, contradice indirectamente el cuestionamiento de los prejuicios étnicos de la que ocasiona el debate, puesto que reivindica la validez orientadora de dichos prejuicios en la vida cotidiana. Desde este punto de vista, la experiencia confirma una moralidad práctica, informal y paralela a la que postula la igualdad y equivalencia social propia, por ejemplo, de los valores impartidos en el sistema educativo público.

\footnotetext{
8 "Palito" es Palito Ortega, cantor comercial de gran ascendiente popular; Víctor Galíndez y Carlos Monzón, fueron destacados boxeadores de las décadas del 70 y 80 . (Humor, 1980, p. 17-18).

${ }^{9} \mathrm{Tal}$ como reza el viejo refrán racista sobre ciertos comportamientos.
} 
Humor, por su parte, atenta al tenor conflictivo de tales opiniones, acota al pie de la carta comentada que dichas "actitudes ferrocarrílicas" (sic) era dable encontrarlas también en sujetos de tipo nórdico. No se atreve a calificar las expresiones de su autor como discriminatorias o racistas, sino que se limita a señalar que lo actitudinal permanece separado de lo étnico y tiene relación con el seguimiento o no de las pautas de comportamiento establecidas en la sociedad.

En resumen, las posturas de los autores de las cartas oscilan, de la crítica con velado sentido político -como tematización de las cuestiones atinentes a lo público- (carta de la lectora que abrió la controversia), a la defensa del carácter autónomo de cualquier función (o huella) social del humor en tanto es ejercido por profesionales en la materia, matizada en un tercer caso con el reconocimiento de cierta responsabilidad del humorista desde lo que se entiende es su lenguaje específico de intervención social, la sátira y el humor. ${ }^{10}$

En definitiva, el intento de la lectora de instalar un debate (político) sobre un tema sensible pero ocultado de la agenda pública, el del racismo y la segregación social, es desestimado. Ni los autores ni la mayoría de los lectores intervinientes en el debate asumen cualquier faceta problemática respecto del "Romancero...", por fuera de lo ficcional, en sintonía con la defensa de la tira emprendida por la revista.

\section{Conclusiones}

La revista Humor, heredera a su modo de otras revistas y continuadora del formato de la prensa gráfica de humor político y humor costumbrista, comenzó su andadura durante la más cruenta dictadura de la historia argentina. Circunstancia que condicionó sus primeros pasos pero no pudo detener su dinámica ascendente, compartida por la capacidad de sus creadores y por el temprano apoyo de los lectores, fueran "seguidores" o nuevos.

De entre estos últimos, abordamos un segmento particular, los lectores-correspondientes de la revista. Su estudio permitió dar cuenta de la decisiva relación de Humor con la porción de su público lector más activa, la que escribió y pudo ver impresas sus inquietudes en "Quemá esas cartas". Una de las razones principales del éxito editorial de la revista de Cascioli radicó en volverse un espacio donde fue posible establecer lazos comunicativos interrumpidos. Un foro de intercambio y discusión -regulado, como en todo medio-, que supo alojar, en un medio de orientación masiva, voces contrastantes con la discursividad oficial. Pero también con los debates intelectuales, puesto que se trató de las opiniones de "hombres corrientes" de las clases medias

\footnotetext{
${ }^{10}$ Autonomía que desde el sentido común dominante conjuraría, como "arte por el arte", cualquier constricción material y simbólica de las clases dominantes, por una parte, y de las exigencias de la producción de contenidos consumidos masivos, consumidos por las mayorías, por otra.
} 
urbanas. En efecto, la revista trató de interpelar a lectores que, como definía una antecesora de Humor, Chaupinela, "tenían como preocupación fundamental trabajar para vivir" (ABREVAYA, 1978) en una etapa de desmovilización política y social. “Quemá esas cartas” llegó a convertirse en un espacio destacado de articulación de opiniones, cuando no sobraban en la prensa, menos aun en la masiva, oportunidades expresivas de este género.

Los casos considerados permitieron ver el funcionamiento de "Quemá esas cartas", dando cuenta de episodios que pusieron en juego la credibilidad de la revista ante los lectores. En la polémica de los chistes sobre el genocidio judío, Humor se vio sometida a una situación interpelativa que no pudo eludir, porque implicaba su razón de ser como publicación humorística. El dilema de la representación humorística del horror, que causara la controversia cedió lugar, por influencia de la coyuntura, a una discusión sobre la asimilación de la minoría judía en Argentina, atizada por la prensa a raíz del caso Timerman. Para Humor, el incidente promovió la primera sistematización de las bases de su proyecto desde su aparición, redundante en una suerte de estatuto del tipo de ejercicio humorístico alentado en sus páginas. Pero también originó una panoplia de opiniones contrastantes entre los lectores, movilizados por la consigna participativa de la revista, pero divididos ante los tópicos en debate.

El segundo momento controversial, alrededor de la inquietante saga del Eustaquio y su partenaire "negrazo", comprometió una ficcionalización humorística de la experiencia cotidiana de los habitantes urbanos, y de los criterios de normalidad y de desajuste que la orientan. En tanto involucró la figura estigmatizada del "cabecita negra", con que se definió a las clases populares, convocó una vez más -tras la discusión derivada sobre la asimilación judía- la cuestión étnico-clasista como problema decisivo de la integración social del país. El subsiguiente debate en "Quemá esas cartas", originado en la intervención de una lectora que intentó reponer el sesgo político a la cuestión, fue desacreditado por Humor en nombre de una condena genérica de todo racismo que invisibilizó la problemática local. Los lectores, en su mayoría, ratificaron esa postura y sancionaron desde su sentido común -informado por las convenciones socialmente dominantes- la inadecuación de asignar significaciones sociopolíticas al humorismo como labor profesional.

Estos debates permitieron poner de manifiesto, asimismo, que el análisis de las producciones humorísticas exige atender las múltiples significaciones sociales posibles en ellas, como cifra de su eventual eficacia. También, que el humor no mantiene una relación unívoca con lo moral. Los casos abordados muestran, en la persona del lectorado de la revista, que la comicidad sobre cuestiones socialmente intrincadas es posible, en tanto su referente no nos parezca (en materia moral) inadecuado para el ejercicio humorístico.

Un denominador común de ambos entredichos es que fueron episodios en los que se aludieron las bases sobre las que se conforma el orden social, en la forma de un sistema de diferencias que contempla un otro, incluido como excluido. Sendas figuras, la del judío y la del 
"cabecita negra", ocuparon ese lugar simbólico tras los argumentos concretos del debate entre la revista, las entidades comunitarias y los lectores. Ello en el contexto banal y "bajo cultural" de una revista de entretenimientos como Humor, lo cual no es un aspecto menor de su repercusión en el marco de la prensa de su tiempo.

\section{Referencias}

ABREVAYA, A. R. El mejor humor de Chaupinela. Buenos Aires: Ediciones de la Urraca, 1978.

AVELLANEDA, Andrés. Censura, autoritarismo y cultura: Argentina 1960-1983. Buenos Aires: Centro Editor de América Latina, 1986.

BARROMI, Joel. Israel frente a la dictadura militar argentina: el episodio de Córdoba y el caso Timerman. In: SENKMAN, Leonardo; SZNAJDER, Mario. (Ed.). El legado del autoritarismo: derechos humanos y antisemitismo en la Argentina contemporánea. Buenos Aires: Grupo Editor Latinoamericano, 1995. p. 325-351.

BOLTANSKI, Luc. El Amor y la justicia como competencias: tres ensayos de sociología de la acción. Buenos Aires: Amorrortu, 2000.

CALVEIRO, Pilar, Poder y desaparición, Buenos Aires: Colihue, 2004.

CARBONE, Rocco. El imperio de las obsesiones. Buenos Aires: UNQ, 2007.

FREUD, Sigmund. Lo siniestro. In: FREUD, Sigmund; HOFFMAN, E. T. A. Lo siniestro/El hombre de la arena. Buenos Aires: Ediciones Noé, 1973. p. 5-58.

GORINI, Ulises. La rebelión de las madres: historia de las Madres de Plaza de Mayo (1976-1983). Buenos Aires: Norma, 2006.

GUBER, Rosana. Identidad social villera: resignificación social de un estigma. Etnia, Buenos Aires, n. 32, p. 81-100, julio/diciembre 1984.

LEFEBVRE, Henri. Introducción a la Modernidad. In: . Obras de Henri Lefebvre (posteriores a 1958), II/El marxismo sin mitos. Buenos Aires: A. Peña Lillo, 1967. p. 447-660.

MATALLANA, Andrea. Humor y política: un estudio comparativo de tres publicaciones de humor político. Buenos Aires: Eudeba, 1999.

O'DONNELL, Guillermo. Democracia en Argentina: micro y macro. In: OSZLAK, Oscar. Proceso, crisis y transición democrática/1. Buenos Aires: CEAL, 1987. p. 13-30.

OSZLAK, Oscar. El derecho al espacio urbano. Buenos Aires: CICSO, 1982.

TEVIK, Jon. Porteñologics: el significado del gusto y la moralidad en la clase media profesional porteña. Buenos Aires: Antropofagia, 2006. 
VÁZQUEZ LUCIO, Oscar. Historia del humor gráfico y escrito en Argentina. Buenos Aires: Eudeba, 1987. t. 2.

\section{Fonte Documental}

Humor, Buenos Aires, 1978-1980, n. 3, ago., 1978; n. 21, oct., 1979; n. 22, oct., 1979; n. 23, nov., 1979; n. 25, dic., 1979; n. 34, mayo 1980; n. 36, jun. 1980; n. 40, ago., 1980; n. 43, sep. 1980.

Mundo Israelita, Buenos Aires, año2, n. 19, oct. 1979.

Nueva Presencia, Buenos Aires, oct., 1979.

Recebido em 30/02/2012

Aprovado em 30/05/2012 